\title{
The Journal and the Bulletin
}

Every member of the College is entitled to these two monthlies, which go all over the world, since about a quarter of the membership is overseas. While the Bulletin is predominantly about College work and membership activities, and goes only to the membership, the Journal is an international medical-scientific journal with a circulation also among non-member subscribers worldwide, particularly among university libraries, medical schools and governmental health rgencies. Because of this extensive sale, and because the Journal is published by the College instead of by a commercial publisher such as Blackwell or Macmillan (as are many journals), the money coming in is enough to finance the whole publishing operation. This is particularly so since tis: editors and assessors give their time and expertise entirely without fees, in some cases amounting to many hours a week of honorary labour, although all the editors (for instance) are also in clinical practice. The financial effect is that not one penny of a member's subscription goes to the production and mailing of these two journals to members, indeed, some of the Journal's 'profit' can be applied to reducing the cost of other College publications, which are often sold at a loss.

The Editor is the College officer responsible for both monthlies. He is elected annually under the bye-laws. He is assisted on the business side by the Business Affairs SubCommittee of the Executive and Finance Committee, and on the literary and policy side by the associate editors appointed by Council. $\mathrm{He}$ appoints all the assistant editors, named at the front of each issue, to do the hard work of technical editing and proof-reading and commissioning special articles, and general sharing in the day-to-day work of producing a journal. He also chooses the assessors, named on completion of each volume, who from their specialist knowledge advise on the qualities of the 500 or so papers submitted annually - just over a third will be accepted for publication.

The final choice of papers is entirely the Editor's because the whole policy of the Journal is his policy, his responsibility, although he may delegate. Different editors may have different policies, just as they may listen (or not) to different advisers. In my opinion the Journal is firstly for spreading news of new clinical observations and new neuroscience experiments of direct relevance to the practice of all branches of clinical psychiatry. It is also for spreading new hypotheses of direct relevance, and for reviewing progress in one field or another from time to time. Secondly, it has a stimulatory function, directing attention to neglected problems in psychiatry, or reminding, through rare case presentations, of possibilities in the daily clinic. Thirdly, it should offer encouragement to psychiatrists doing research under difficulties, possibly in Africa or Asia, and to junior doctor trainees taking their first faltering steps. It should also include some matter of educational value to the trainee. While the contents of each volume should show a balance between different interests and different sub-specialties, they primarily reflect the areas of new growth in the subject, partly by editorial intention and partly because more submitted papers are in these areas.

To illustrate this policy in action I looked back through twelve issues, July 1981 to June 1982 (vols 139 and 140). There were 178 original articles in about 1,200 pages. Of these, 11 (occupying 54 pages) were biochemical and 29 (or 113 pages) were on psychopharmacology, mostly, in fact, on treatment-the proper use of lithium and antidepressants or of propranolol in schizophrenia-matters which any practising general psychiatrist might need to know. There were also seven papers on endocrinology, some clinical (acromegaly, psychiatric aspects of diabetes), some tests involving the laboratory (e.g. dexamethasone). All this neuroscience together filled just over 200 pages or about one-sixth of the space. In the same two volumes there were articles on such subjects as cognitive therapy in depression, symptomatology of puerperal illnesses, children who cause fires, hysterectomy as a cause of psychiatric illness and the use of nortriptyline in the elderly.

What Psychological Medicine calls editorials, and the Lancet, leaders, are commissioned short reviews. In our twelve issues there were six such articles, five under the heading 'Comments' and one under 'Point of View'; there were also three essays on books ('Reading About....' and 'Books Reconsidered'), on psychoanalysis, family therapy, and R. D. Laing. There were also at least nine longer subject reviews (not necessarily labelled specially as such), and at least nine case reports.

Spontaneous criticism from readers is very sparse and mostly not based on what has actually been published in each volume, but on a longing to be helped with the difficult problems of psychotherapy and relations with patients. Some suggest papers on philosophy or on religions, or further rewriting on dynamic psychotherapies where an enormous book and journal literature already exist. We need to think of new ways of presenting these problems and new ways of studying them. Nobody really knows the answers yet, and faith is no substitute for fact.

J. L. Crammer 